\title{
Growth rate was greater with fluticasone propionate than with beclomethasone dipropionate in children with chronic asthma
}

\author{
de Benedictis FM, Teper A, Green RJ, et al, for the International Study Group. Effects of 2 inhaled corticosteroids on growth. \\ Results of a randomized controlled trial. Arch Pediatr Adolesc Med 2001 Nov;155:1248-54.

\section{QUESTION: In children with chronic asthma, what are the effects of fluticasone propionate compared with those of beclomethasone dipropionate on growth rates?}

Design

Randomised (allocation concealed*), blinded (unclear),* controlled trial with 12 months of follow up.

\section{Setting}

32 centres in 7 countries: The Netherlands, Hungary, Italy, Poland, Argentina, Chile, and South Africa.

\section{Patients}

343 children who were 4 to 11 years of age (mean age $8 \mathrm{y}, 72 \%$ boys); had a sexual maturity rating of Tanner stage 1; required treatment with fluticasone propionate, 100 to $200 \mu \mathrm{g} /$ day, or beclomethasone dipropionate or budesonide, 200 to $500 \mu \mathrm{g} /$ day, for $\geqslant 8$ weeks before study entry at a constant dosage for $\geqslant 4$ weeks before the run-in period; had a mean morning peak expiratory flow rate (PEFR) during the last 7 days of the run-in period of $\leqslant 85 \%$ of their maximum achievable response after using a metered dose inhaler containing albuterol sulphate, $400 \mu \mathrm{g}$; and had an asthma symptom score $\geqslant 1$ or required albuterol $\geqslant 1$ time daily on $\geqslant 4$ days during the last 7 days of the run-in period. Exclusion criteria were intermittent asthma or disorders that could affect growth, receipt of oral or parenteral steroids, or

Perugia, Italy.

debened@unipg.it. admission to hospital with respiratory disease in the 4 weeks before the run-in period. $81 \%$ of patients were included in the analysis for growth rate.

\section{Intervention}

After the 2 week run-in period, during which patients continued to receive their existing inhaled corticosteroid treatment and albuterol sulphate on an asneeded basis, they were allocated to inhaled fluticasone propionate, $200 \mu \mathrm{g}$ twice daily $(\mathrm{n}=170)$, or beclomethasone dipropionate, $200 \mu \mathrm{g}$ twice daily $(\mathrm{n}=173)$, by dry powder inhaler for 52 weeks.

\section{Main outcome measure}

Change in height (growth rate) as measured by stadiometry.

\section{Main results}

Patients $(\mathrm{n}=277)$ with $\geqslant 2$ data points (at randomisation and on or after 16 wks of treatment) who did not reach a Tanner stage of $\geqslant 2$ during the study and who did not have other factors that would probably affect the measurement of growth (eg, poor compliance or use of systemic corticosteroids) were included in the analysis. Adjusted mean growth rate was greater in the fluticasone group than in the beclomethasone group (table).

\section{Conclusion}

The growth rate of children with chronic asthma was greater with fluticasone propionate than with beclomethasone dipropionate.

*See glossary.

\section{COMMENTARY}

The well designed study by de Benedictis $e t$ al addressed an important question and showed that at 12 months, children with chronic asthma treated with fluticasone were about $1 \mathrm{~cm}$ taller than those treated with beclomethasone. Children treated with fluticasone showed better lung function than did those treated with beclomethasone (adjusted mean PEFR $282.5 v 267.3 \mathrm{l} / \mathrm{min}, \mathrm{p}<0.001$ ), but groups did not differ for asthma symptom scores, use of rescue albuterol, exacerbations, or adverse events (including assessment of adrenal axis function, although follow up was $<80 \%$ for this outcome). However, the study was not powered to show equivalency for these outcomes.

The primary analysis assesses the efficacy of treatment for asthma and how it affects growth rate. The intention-to-treat analysis gives similar, although less striking, results (difference in means $0.7 \mathrm{~cm} / \mathrm{y}, 95 \%$ CI 0.13 to 1.26 , in favour of fluticasone). Thus, we can safely conclude that fluticasone, $400 \mu \mathrm{g} / \mathrm{day}$, was associated with a greater growth rate than was the same dose of beclomethasone.

How can we explain the difference in growth rates? One obvious reason may be the drugs themselves, in part because of a difference in systemic bioavailability. Another reason may be the enhanced asthma control achieved in the fluticasone group. The unanswered question is whether the results for growth rate continue to hold true when equivalent drug potency is addressed; at a $2: 1$ ratio for potency, children treated with fluticasone propionate, $400 \mu \mathrm{g} / \mathrm{day}$, received twice as much anti-inflammatory medication than did those treated with beclomethasone dipropionate, $400 \mu \mathrm{g} / \mathrm{day}$. If the drug is responsible for the effect on growth, fluticasone will have a lesser effect on growth than an equipotent dose of beclomethasone of $800 \mu \mathrm{g} /$ day. Will this effect be annihilated by enhanced lung function and asthma control achieved in children treated with beclomethasone, $800 \mu \mathrm{g} /$ day? Such a comparison would better address whether the drug itself or asthma control is responsible for the difference in growth between groups. Until then, what should we do? In children whose asthma is not well controlled with beclomethasone, $400 \mu \mathrm{g} /$ day, a switch to fluticasone, $400 \mu \mathrm{g} /$ day, with tapering to the minimal effective dose would be an interesting option.

Francine M Ducharme, MD McGill University, Montreal, Quebec, Canada 